\title{
The Southern Ocean Sea Surface Temperature Response to Ozone Depletion: A Multimodel Comparison ${ }^{\mathscr{O}}$
}

\author{
W. J. M. Seviour,${ }^{\mathrm{a}, \mathrm{b}}$ F. CODron, ${ }^{\mathrm{c}}$ E. W. DodDridge, ${ }^{\mathrm{d}}$ D. FERreira, ${ }^{\mathrm{e}}$ A. GNANAdesikan, ${ }^{\mathrm{a}}$ \\ M. Kelley, ${ }^{\text {f }}$ Y. Kostov, ${ }^{g}$ J. Marshall,${ }^{d}$ L. M. Polvani,,${ }^{h, i}$ J. L. Thomas, ${ }^{a}$ And D. W. Waugh ${ }^{a, j}$ \\ ${ }^{a}$ Department of Earth and Planetary Sciences, The Johns Hopkins University, Baltimore, Maryland \\ ${ }^{\mathrm{b}}$ School of Geographical Sciences, University of Bristol, Bristol, United Kingdom \\ ${ }^{\mathrm{c}}$ LOCEAN/IPSL, Sorbonne Université, CNRS, IRD, MNHN, Paris, France \\ ${ }^{\mathrm{d}}$ Department of Earth, Atmospheric, and Planetary Sciences, Massachusetts Institute of Technology, Cambridge, Massachusetts \\ ${ }^{\mathrm{e}}$ Department of Meteorology, University of Reading, Reading, United Kingdom \\ ${ }^{\mathrm{f}}$ NASA Goddard Institute for Space Studies, New York, New York \\ ${ }^{\mathrm{g}}$ Department of Physics, University of Oxford, Oxford, United Kingdom \\ ${ }^{\mathrm{h}}$ Applied Physics and Applied Mathematics Department, Columbia University, New York, New York \\ ${ }^{\mathrm{i}}$ Department of Earth and Environmental Science, Lamont-Doherty Earth Observatory, Columbia \\ University, Palisades, New York \\ ${ }^{\mathrm{j}}$ School of Mathematics, University of New South Wales, Sydney, New South Wales, Australia
}

(Manuscript received 8 February 2019, in final form 14 May 2019)

\begin{abstract}
The effect of the Antarctic ozone hole extends downward from the stratosphere, with clear signatures in surface weather patterns including a positive trend in the southern annular mode (SAM). Several recent studies have used coupled climate models to investigate the impact of these changes on Southern Ocean sea surface temperature (SST), notably motivated by the observed cooling from the late 1970s. Here we examine the robustness of these model results through comparison of both previously published and new simulations. We focus on the calculation of climate response functions (CRFs), transient responses to an instantaneous step change in ozone concentrations. The CRF for most models consists of a rapid cooling of SST followed by a slower warming trend. However, intermodel comparison reveals large uncertainties, such that even the sign of the impact of ozone depletion on historical SST, when reconstructed from the CRF, remains unconstrained. Comparison of these CRFs with SST responses to a hypothetical step change in the SAM, inferred through lagged linear regression, shows broadly similar results. Causes of uncertainty are explored by examining relationships between model climatologies and their CRFs. The intermodel spread in CRFs can be reproduced by varying a single subgrid-scale mixing parameter within a single model. Antarctic sea ice CRFs are also calculated: these do not generally exhibit the two-time-scale behavior of SST, suggesting a complex relationship between the two. Finally, by constraining model climatology-response relationships with observational values, we conclude that ozone depletion is unlikely to have been the primary driver of the observed SST cooling trend.
\end{abstract}

\section{Introduction}

In contrast to the rapidly warming Arctic, sea surface temperature (SST) averaged over the Southern Ocean (SO) has exhibited a multidecadal cooling trend from

Supplemental information related to this paper is available at the Journals Online website: https://doi.org/10.1175/JCLI-D-190109.s1.

Corresponding author: William J. M. Seviour, w.seviour@ bristol.ac.uk the beginning of the satellite record in 1979 (Fan et al. 2014; Armour and Bitz 2015) (although this trend may have reversed since late 2016; Meehl et al. 2019). During the same period, there have also been significant changes in the Southern Hemisphere (SH) atmospheric circulation, including a poleward shift and intensification of the SH midlatitude jet, consistent with a positive trend in the southern annular mode (SAM) (Swart and Fyfe 2012; Hande et al. 2012; Jones et al. 2016). There is mounting evidence that these atmospheric trends are significantly driven by stratospheric ozone depletion (Thompson et al. 2011), the influence of which extends 
downward through the troposphere to the surface. Indeed, the impact of ozone depletion on the SH summertime atmospheric circulation has been shown to dominate that of rising greenhouse gas concentrations over the last several decades (Polvani et al. 2011; Gerber and Son 2014), although there remains significant uncertainty as to the contribution of natural variability (Thomas et al. 2015). However, it is an open question whether the cooling trend in SO SST is caused by these atmospheric circulation changes (and, in turn, may be linked to ozone depletion), whether it caused by other processes, or if it is simply a result of natural internal climate variability. Answering this question will be crucial to predict the future of SO temperatures as the ozone hole heals during coming decades.

A number of studies have used coupled climate models to investigate the impact of ozone depletiondriven atmospheric circulation trends on the SO. These have either compared annually repeating "ozone hole" and control (pre-ozone depletion) simulations (Sigmond and Fyfe 2010; Bitz and Polvani 2012), or used simulations with time-varying historical or predicted future ozone concentrations (Smith et al. 2012; Sigmond and Fyfe 2014; Solomon et al. 2015). All such studies have found that ozone depletion leads to a surface warming [see review by Previdi and Polvani (2014)], concluding that ozone depletion has acted to oppose the observed cooling trend rather than driving it. These findings were surprising given that, on interannual time scales, a positive phase of the SAM is known to induce a surface cooling poleward of $50^{\circ} \mathrm{S}$, a response that is understood to be predominantly forced by increased equatorward Ekman transport of cold waters near Antarctica (Hall and Visbeck 2002; Ciasto and Thompson 2008). Motivated by this interannual SAM-SST relationship, Goosse et al. (2009) proposed that the ozone-driven positive SAM trend may indeed be responsible for the observed SST cooling, a conclusion that opposes the findings from coupled climate models.

Recent advances have been made toward reconciling these seemingly contradictory results. In particular, studies have focused on the time dependence of the SST response to ozone depletion through the calculation of "climate response functions" (CRFs), the transient response to an instantaneous step change in ozone concentrations (Marshall et al. 2014). By using this idealized ozone forcing, CRFs can reveal more clearly the time scales and mechanisms of the response than simulations with more realistic transient ozone changes. Ferreira et al. (2015) calculated CRFs in two coupled models: CCSM3.5 and an idealized coupled MITgcm configuration. They showed that on shorter time scales (months to years), the ozone depletion CRF is characterized by
SO SST cooling, consistent with the SAM-SST interannual relationship. On longer time scales (years to decades) this cooling is replaced by a warming associated with Ekman upwelling of warm water from depth. Seviour et al. (2016) showed that this two-time-scale CRF also exists in the GFDL-ESM2Mc model, which has much greater variability associated with deep convection in the Weddell Sea (Cabré et al. 2017). However, there are large differences between the CRFs of these three models. For instance, the initial cooling period lasts about 20 years in MITgcm, 25 years in GFDLESM2Mc, but just 5 years in CCSM3.5. The length of this cooling period may have a profound effect on our understanding of the influence of ozone depletion on historical SST. However, given that CRFs had been calculated in just three models (and one of these, MITgcm, used a highly idealized configuration), it is not clear how robust this value is.

An alternative method to estimate the CRF, using lagged linear regression between the SAM and SST, was put forward by Kostov et al. (2017). Unlike the stepresponse simulations described above, this method makes use of preexisting control simulations. While Kostov et al. (2017) found a two-time-scale CRF to exist in many of the models included in phase 5 of the Coupled Model Intercomparison Project (CMIP5), they again noted large intermodel differences. They related differences in models' short- and long-term SST responses to their climatological Southern Ocean meridional SST gradient and vertical temperature inversion, respectively. These relationships are physically plausible if, as proposed by Ferreira et al. (2015), the shortterm response is largely driven by meridional Ekman transport, and the long-term response is driven by anomalous upwelling of warm subsurface water. However, the climatology-response relationships shown by Kostov et al. (2017) explained only about $50 \%$ and $20 \%$ of the intermodel variance of the short- and long-term responses, respectively, indicating that several other factors may also play an important role. Indeed, Doddridge et al. (2019) proposed that the wind-driven upwelling is opposed by an eddy-driven circulation (a process known as eddy compensation), thereby limiting the ability of this upwelling to drive the long-term SST warming. The short-term SST cooling response may also be significantly affected by increased low cloud cover associated with a positive SAM, as well as by surface freshening leading to a reduction in vertical mixing (Ferreira et al. 2015; Seviour et al. 2017a), both of which may add to intermodel variance in responses.

Here we provide a synthesis of the recent ozone depletion CRF studies described above, alongside new ensembles of CRF simulations using three additional 
TABLE 1. Models for which ozone depletion CRF simulations have been performed.

\begin{tabular}{lccc}
\hline \multicolumn{1}{c}{ Model } & Ensemble size & Simulation length (yr) & Reference \\
\hline MITgcm & 20 & 40 & Ferreira et al. (2015) \\
CCSM3.5 & $6(+20$ for first 32 months) & 20 & Ferreira et al. (2015) \\
GISS-E2.1 & 8 & 60 & Doddridge et al. (2019) \\
GFDL-ESM2Mc (GM200) & 24 & 45 & Seviour et al. (2016) \\
GFDL-ESM2Mc (GM600) & 12 & 45 & This study \\
IPSL CM5A-MR & 24 & 25 & This study \\
\hline
\end{tabular}

coupled climate models. This allows us to identify the robust aspects of the simulated SST response to ozone depletion, as well as to determine intermodel differences. We also discuss these CRFs in the context of projected SST changes under realistic time-varying ozone concentrations. We go on to compare these fully nonlinear ozone depletion CRF simulations with SAMSST CRFs calculated from the same models using the lagged linear regression method of Kostov et al. (2017). Note that a direct comparison between these two approaches was not previously possible because ozone depletion CRF simulations have not been performed using any of the CMIP5 models considered by Kostov et al. (2017). To examine the sensitivity of models' CRFs to their climatology, we vary the subgrid-scale eddy advection, which controls the strength of the climatological temperature inversion, in a single model. In doing so, we are able to isolate the role of the temperature inversion in determining the CRF, while keeping other factors (such as cloud-circulation feedbacks) fixed. Finally we discuss the relationship between models' SST and Antarctic sea ice responses.

Our paper is organized as follows: Section 2 describes the model simulations used, as well as the two approaches for estimating CRFs. Section 3a gives a comparison of fully nonlinear ozone depletion CRFs, section $3 \mathrm{~b}$ compares these with linear SAM-SST CRFs, and section $3 \mathrm{c}$ focuses on the relationship between model climatologies and their CRFs. Section 4 discusses the results in the context of observed SO trends, and conclusions are presented in section 5 .

\section{Models and methodology}

\section{a. Models and ozone depletion CRF simulations}

Ozone depletion CRFs are calculated using coupled climate model simulations in which the annual cycle of ozone concentrations is abruptly changed from pre-ozone depletion levels to contemporary "ozone hole" levels. All other forcings are kept constant at preindustrial levels. To separate the forced response to ozone depletion from internal climate variability, an ensemble of simulations with varying initial conditions is performed. The six ensembles of CRF simulations compared here are detailed in Table 1. For full descriptions of the previously published simulations the reader is directed to the appropriate references. It is noteworthy that, unlike other models, the MITgcm simulations used a highly idealized "double Drake" configuration (consisting of an aquaplanet with two "sticks" of land extending from the North Pole to $35^{\circ} \mathrm{S}$, separated by $90^{\circ}$ longitude). The MITgcm simulations' ocean mixed layer also lacks a parameterization of vertical mixing, while the atmosphere does not have an explicit representation of ozone and just a single layer representing the stratosphere; the ozone perturbation is performed by introducing a seasonal reduction of shortwave absorption in this layer.

The CRF simulations with L'Institut Pierre-Simon Laplace (IPSL) CM5A-MR have not been previously published. IPSL CM5A-MR is the midresolution version of the IPSL-CM5A model (Dufresne et al. 2013) and has an atmospheric resolution of $1.25^{\circ}$ with 39 vertical levels (including a resolved stratosphere), and an ocean resolution of $2^{\circ}$ with 21 levels. A 24-member ensemble of 25-yr CRF simulations was performed, all initialized from the long (300 year) equilibrated CMIP5 preindustrial control simulation. The starting dates were taken at least 5 years apart and chosen to ensure that 1 ) there was no large ensemble-mean trend in the Southern Ocean SST and sea ice in the corresponding control 25yr periods, and 2) there was no spurious sampling of multidecadal variability in the Atlantic (AMO) or Pacific [interdecadal Pacific oscillation (IPO)]. For each ensemble member, the prescribed seasonal cycle of ozone concentration was changed on 1 January of the starting year from preindustrial to that of year 2000 used in the CMIP5 historical simulations.

We also present an ensemble of CRF simulations using the GFDL-ESM2Mc model as in Seviour et al. (2016), but with a perturbation to the model's subgridscale eddy parameterization. The purpose of this ensemble is to study the effect of changing the climatological ocean state while keeping the atmospheric response approximately fixed. Specifically, we increase the minimum value of the diffusion coefficient $A_{\mathrm{GM}}$ in the Gent-McWilliams eddy advection scheme (Gent and 
McWilliams 1990) from 200 to $600 \mathrm{~m}^{2} \mathrm{~s}^{-1}$ (herein these experiments are labeled GM200 and GM600). Under this parameterization scheme $A_{\mathrm{GM}}$ varies spatially depending upon the meridional gradient of vertical shear between 100 and $2000 \mathrm{~m}$, with a minimum and maximum value imposed (fixed at $1400 \mathrm{~m}^{2} \mathrm{~s}^{-1}$ ). Because the resulting overturning scales as the product of the isopycnal slope and the buoyancy frequency, changing the minimum value has a large impact in the weakly stratified Southern Ocean, but very little effect across much of the rest of the global ocean (Thomas et al. 2018).

\section{b. SAM climate response functions}

An alternative method for estimating CRFs, using models' internal climate variability, was put forward by Kostov et al. (2017), and is briefly described here. The evolution of SO SST in a control simulation $\operatorname{SST}_{\mathrm{cntrl}}(t)$ can be expressed as a convolution of the SAM forcing with a quasi-Green's function $G(t)$,

$$
\begin{aligned}
\operatorname{SST}_{\mathrm{cntrl}}(t) & =\int_{0}^{+\infty} G\left(t^{\prime}\right) \operatorname{SAM}_{\mathrm{cntrl}}\left(t-t^{\prime}\right) d t^{\prime}+\varepsilon \\
& \approx \int_{0}^{t_{\max }} G\left(t^{\prime}\right) \operatorname{SAM}_{\mathrm{cntrl}}\left(t-t^{\prime}\right) d t^{\prime}+\varepsilon
\end{aligned}
$$

where $\mathrm{SAM}_{\mathrm{cntrl}}(t)$ is the SAM index normalized by its standard deviation, $t_{\max }$ is an imposed maximum cutoff lag, and $\varepsilon$ is residual noise. Importantly, the underlying assumption of Eq. (1) is that the ocean response to SAM forcing is linear, such that there is not a significant feedback between the SAM and SO SST, at least on the relevant time scales from years to decades. Equation (2) can be discretized to give

$$
\begin{aligned}
\operatorname{SST}_{\mathrm{cntrl}}(t) & =\sum_{i=0}^{I} G\left(t_{i}^{\prime}\right) \mathrm{SAM}_{\mathrm{cntrl}}\left(t-t^{\prime}\right) \Delta t^{\prime}+\varepsilon, \quad \text { with } \\
t_{I}^{\prime} & =t_{\text {max }},
\end{aligned}
$$

where each interval $\Delta t^{\prime}$ is taken to be 1 year, and the coefficients $G\left(t_{i}^{\prime}\right)$ represent the response at different time lags to a SAM impulse of one standard deviation. Multiple linear least squares regression between the SST time series and lagged SAM time series is used to estimate each $G\left(t_{i}^{\prime}\right)$ for $i=0,1, \ldots, I$. Integrating $G\left(t_{i}^{\prime}\right)$ in time then gives the SO SST step-response function (CRF)

$$
\mathrm{CRF}_{\mathrm{SAM}}(t)=\sum_{i=0}^{I} G\left(t_{i}^{\prime}\right) \Delta t^{\prime} \quad \text { with } \quad t_{I}^{\prime}=t_{\max } .
$$

Following Kostov et al. (2017), we vary the value of $t_{\max }$ $(50,75,100$, and 150 years $)$ and select shorter subsets of the control simulation time series to obtain a range of fits. We also calculate the uncertainty in each least squares fit. These uncertainties are combined in quadrature to obtain an overall uncertainty estimate in $\mathrm{CRF}_{\mathrm{SAM}}(t)$.

The impact of ozone depletion on the SAM is highly seasonal, with the largest surface impacts in the austral summer and autumn, lagging the seasonal cycle of ozone forcing by approximately 3 months (e.g., Thompson and Solomon 2002; Polvani et al. 2011). Hence, in order to make the closest possible comparison with the ozone depletion CRF simulations, we set $\mathrm{SAM}_{\text {cntrl }}(t)$ to represent the December-May-averaged SAM index. We here define the SAM index as the difference between the zonally averaged sea level pressure at $40^{\circ}$ and $65^{\circ} \mathrm{S}$, as in Swart et al. (2015).

\section{c. Inferring the response to time-dependent forcing}

Although CRFs represent the response to an idealized instantaneous ozone hole, they can be related to changes under realistic time-varying ozone concentrations by linear convolution theory (Hasselmann 1993; Kostov et al. 2018). Given a forcing function $F(t)$, and a CRF for the step response per unit forcing, then the timedependent forced SST response is given by

$$
\operatorname{SST}(t)=\int_{0}^{t} \operatorname{CRF}\left(t-t^{\prime}\right) \frac{\partial F}{\partial t}\left(t^{\prime}\right) d t^{\prime}+\varepsilon
$$

For the case of ozone depletion, we take $F(t)$ to be the October-mean polar cap $\left(60^{\circ}-90^{\circ} \mathrm{S}\right)$ averaged total column ozone in Dobson units (DU); hence the dimensions of the CRF are $\mathrm{KDU}^{-1}$. In practice, the lower bound of the integral in Eq. (2), $t=0$, is taken to be at some time when the forcing can be assumed negligible; here we take this to be the year 1955, before which stratospheric ozone changes are likely to have been very small (e.g., Cionni et al. 2011).

\section{Results}

\section{a. Intermodel comparison of ozone climate response functions}

The ensemble-mean responses of zonal-mean wind stress are broadly similar in all six ensembles of CRF simulations, consisting of a decline in wind stress equatorward of the climatological maximum and a wind stress increase poleward of the maximum (Fig. 1). These wind stress responses occur rapidly within the first year of the ozone perturbation, after which they are approximately constant, although with significant internal variability. This internal variability is reduced, but not 


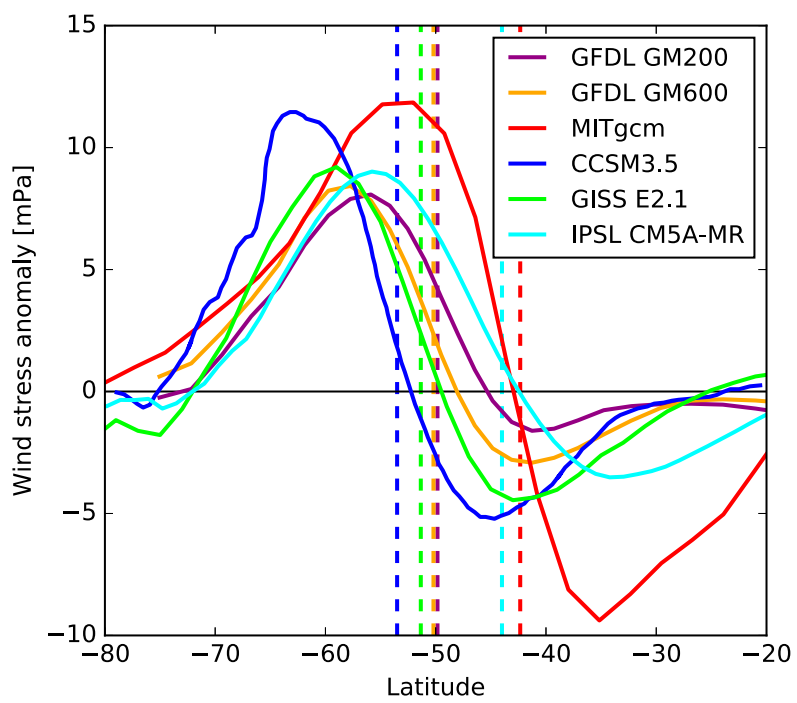

FIG. 1. Ensemble-mean, annual-mean, zonal-mean zonal wind stress anomalies in the ozone CRF simulations of six models. Dashed vertical lines indicate the latitude of maximum wind stress in the control simulation of each model.

completely eliminated, in the ensemble mean (see Fig. S1 in the online supplemental material). Hence the wind stress forcing experienced by the ocean in these CRF simulations can be well approximated by a step function. This pattern of wind stress anomalies is indicative of a poleward shift and strengthening of the extratropical jet, giving an average positive SAM shift of about one standard deviation, a response that is found across a range of climate models (Seviour et al. 2017b). The largest amplitude response is seen in the MITgcm ensemble, which also has a climatological wind stress maximum about $10^{\circ}$ equatorward of the majority of other models; this is perhaps not surprising given the idealized nature of the MITgcm simulations. The IPSL CM5A-MR wind stress maximum is also significantly equatorward of other models, a bias that was also noted in the IPSL CMIP5 simulations (Barnes and Polvani 2013) [note the observed wind stress maximum is at about $52^{\circ} \mathrm{S}$ (Ferreira et al. 2015), close to that in the GFDL-ESM2Mc, GISS-E2.1, and CCSM3.5 models]. Wind stress responses in the GM200 and GM600 simulations are very similar, and their climatological wind stress maxima are almost identical, suggesting that the impact of changing $A_{\mathrm{GM}}$ on the atmospheric circulation and its response to ozone depletion is small.

In all models, the zonal- and annual-mean SST response to the ozone step perturbation consists of a warming equatorward of the climatological wind stress maximum (as seen by the positive values above the dashed line in Fig. 2). This response is consistent with the decrease in wind stress in this region, leading to an anomalously poleward Ekman current. Indeed, the magnitude of this warming response appears to be related to the magnitude of the midlatitude wind stress perturbation, being largest in CCSM3.5 and MITgcm. Interestingly, this midlatitude surface warming may be transported to depth by Ekman pumping as well as enhanced ventilation and subduction, and significantly contribute toward an increase in ocean heat content (Solomon et al. 2015).

In contrast to the midlatitude response, the SST response in the SO (poleward of the wind stress maximum), which is the primary focus of this study, is much less robust among models and is further highlighted in Fig. 3a. Within the first 2 years of the perturbation all models show cooling responses, but of varying magnitudes. The majority of the models then show a transition from a SO cooling to a warming over a range of time scales; we can divide these into multidecadal time scales ( $>15$ years: MITgcm, GFDL GM200), decadal time scales (5-15 years: GFDL GM600, GISS-E2.1), and interannual time scales $(<5$ years; CCSM3.5). IPSL CM5A-MR is the only model not to show a transition from a SO cooling to warming in the annual mean, although it has a slow warming trend in winter and spring seasons when there is little wind forcing. Since the IPSL CM5A-MR CRF simulations were only run for 25 years, it is possible that the transition may occur after this time (as it does for GFDL GM200 simulation). It is noteworthy that the two versions of the GFDL-ESM2Mc model, GM200 and GM600, give very different SST responses; the GM200 ensemble has a transition from cooling to warming after about 27 years, while the GM600 has this transition after 13 years. We will return to discuss this difference in section $3 \mathrm{c}$. It should also be noted that some of the initial cooling response in the GM200 ensemble is due to its ensemble average initial SST being slightly cooler than the climatological average, but that a cooling response remains once the effect of these initial conditions is removed (Seviour et al. 2016).

We may use these SST step responses, together with Eq. (5), to infer the response to realistic time-varying ozone changes. Here we use polar cap $\left(60^{\circ}-90^{\circ} \mathrm{S}\right)$ averaged column ozone from a transient simulation of the Whole Atmosphere Community Climate Model (WACCM), from 1955 to 2020 (inset in Fig. 3b). This provides ozone changes that are in close agreement with observed values (Froidevaux et al. 2019). The WACCM simulations follow the REF-C2 scenario specified by the Chemistry-Climate Model Initiative (CCMI), using observed forcings up to 2005, and following the RCP6.0 scenario thereafter. The column ozone time series is 

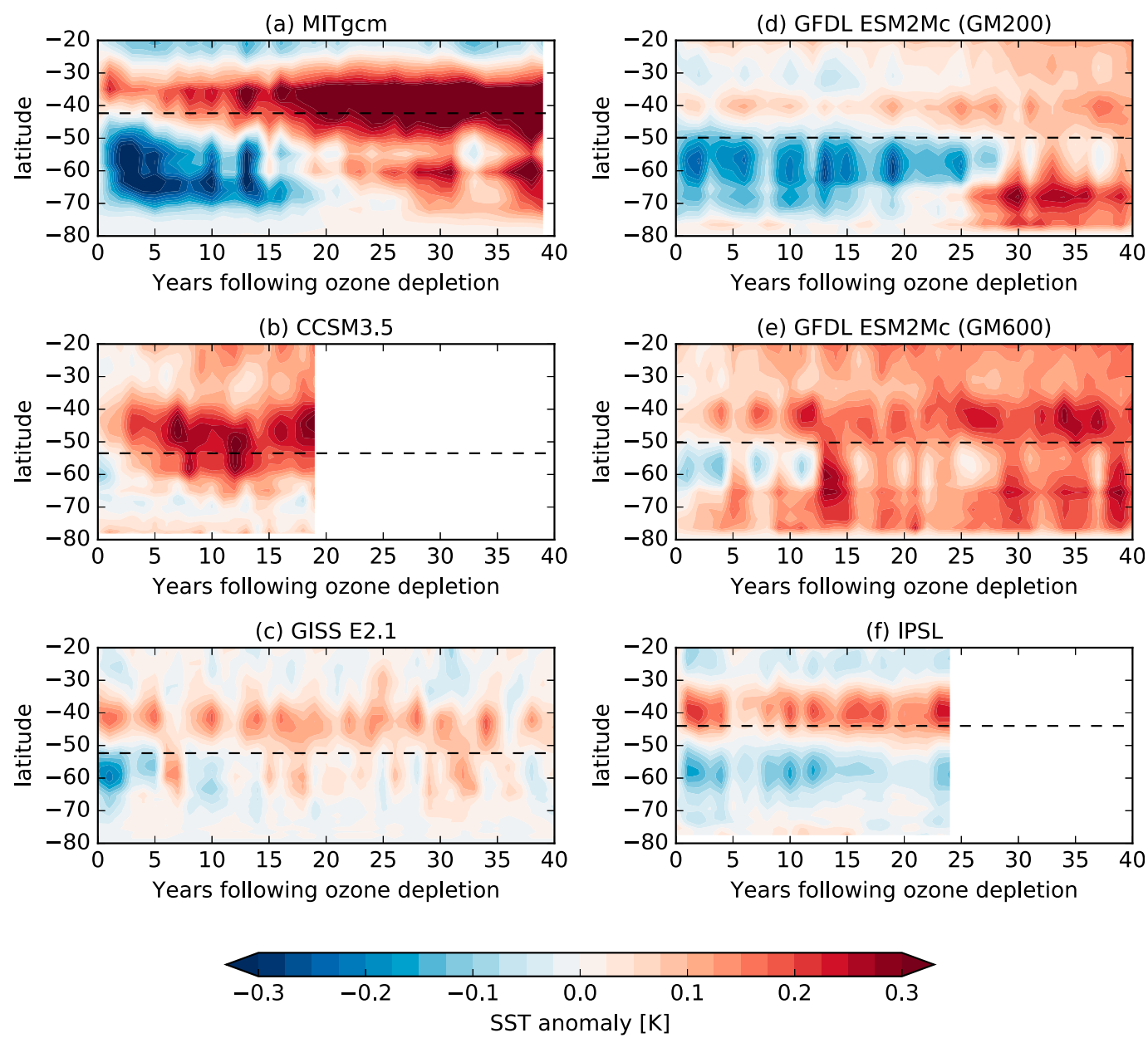

FIG. 2. Ensemble mean, annual-mean, zonal-mean SST anomalies in the ozone CRF simulations of six models. Dashed horizontal lines indicate the latitude of maximum zonal wind stress in the control simulation of each model (as in Fig. 1).

smoothed using a decadal running mean. It is first necessary to scale each CRF by the ozone perturbation for each model; for the case of MITgcm, in which ozone is not explicitly represented, we assume the change is equivalent to the change in WACCM between the years 1960 and 2000. Additionally, we must extrapolate the CRFs such that they are 65 years long (the same length as the ozone signal) in order to be able to perform the full convolution in Eq. (5). To do so we simply assume that the CRF stays at a constant equal to its value in its final year up to year 65 (i.e., we extrapolate a horizontal line from the final value to year 65).

A wide range of predicted forced responses to realistic ozone changes is seen among the different models (Fig. 3b). Even though almost all models show a twotime-scale response with an initial cooling in their CRFs, some models show a monotonic warming in response to realistic ozone changes (CCSM3.5, GFDL GM600), with no cooling period. Note that this model spread is clearly evident at 1980, before any extrapolation beyond the length of CRF simulations is needed. The observed trend in annual-mean SO SST (Fig. S2) consists of a warming of approximately $0.15 \mathrm{~K}$ from the 1950 s until about 1980 (though with large observational uncertainty), followed by a cooling of similar magnitude through 2016 (Fan et al. 2014; Jones et al. 2016). All models show small SST changes from the 1950s to 1970s because the change in ozone forcing is small over this period. The only model to replicate a similar (though weaker in magnitude) multidecadal cooling trend from 1980 is IPSL CM5A-MR, which does not have a twotime-scale CRF (or has a second time scale that is too long to be captured by the CRF simulations). Even models with a multidecadal cooling in their CRF (MITgcm, GFDL GM200) show a transition to a warming trend in the 1990s. This finding is in agreement with 

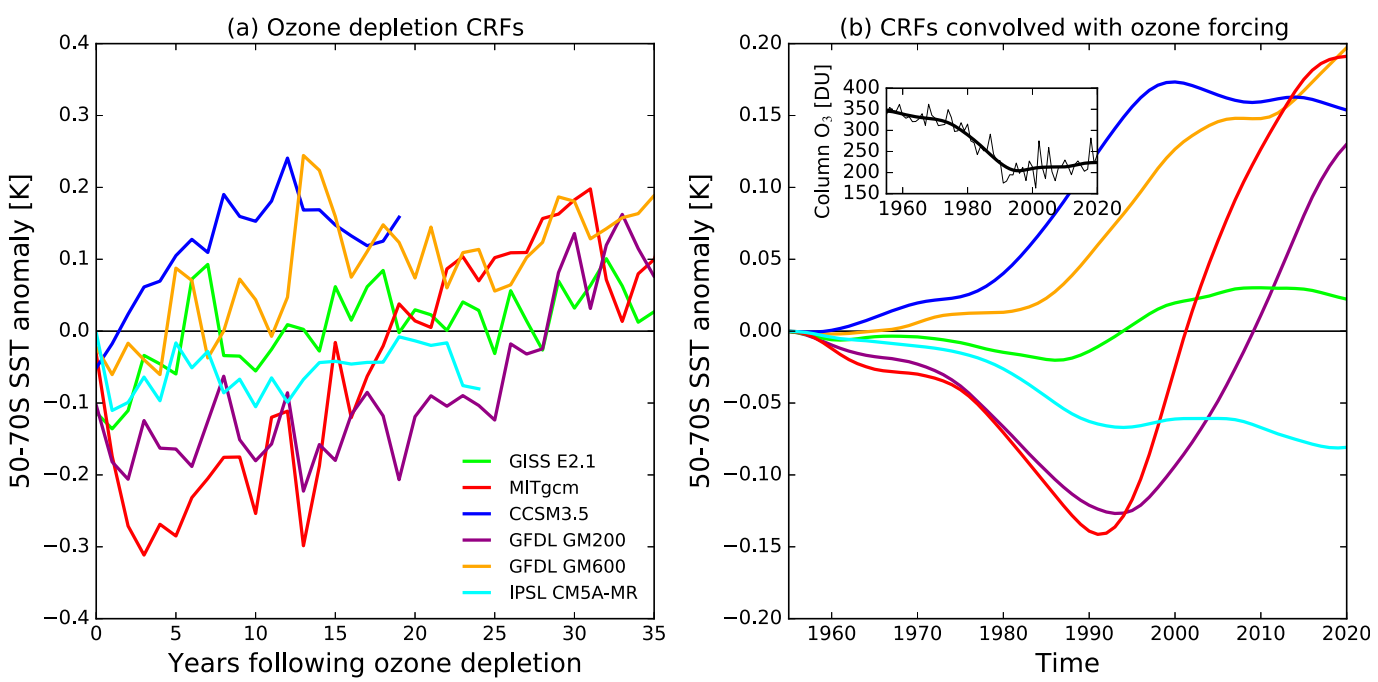

FIG. 3. (a) Ensemble-mean time series of annual-mean SST averaged over the Southern Ocean region $\left(50^{\circ}-70^{\circ} \mathrm{S}\right)$ in each ozone CRF simulation. (b) Convolution of SST CRFs in (a) with ozone forcing [inset shows October-mean polar cap $\left(60^{\circ}-90^{\circ} \mathrm{S}\right)$ column ozone] from 1955 to give the predicted forced SST response to the time-varying ozone forcing. The ozone forcing is taken from a simulation of the WACCM chemistry-climate model.

Kostov et al. (2018), who showed that inferred SAM CRFs (as described in section $2 \mathrm{~b}$ ) convolved with observed SAM trends fail to replicate the SST cooling from 1980 in the vast majority of CMIP5 models. They found that it was only possible to replicate a SST trend as large as observed in those models with a very long transition time scale. In the next section we explicitly compare these inferred SAM CRFs with the fully nonlinear ozone CRFs in each of our six models.

\section{b. Comparison of SAM and ozone CRFs}

SAM CRFs, as described in section $2 b$, represent the predicted SO SST response to a one standard deviation perturbation to the SAM, inferred through lagged linear regression (Kostov et al. 2017). To make a direct comparison with the ozone CRFs described in the previous section, we scale the SAM CRF by the SAM perturbation (measured in standard deviations) induced by ozone depletion in each model's ozone CRF experiments. For the GFDL GM200 and GM600 and IPSL CM5A-MR this is less than one standard deviation, leading to a reduction in the magnitude of the SAM $\mathrm{CRF}$, while for CCSM3.5 the scaling is greater than one standard deviation. The comparison of ozone CRFs and scaled SAM CRFs (with uncertainties calculated as described in section $2 b$ ) is shown in Fig. 4. For all models, with the exception of GFDL GM200, the SAM CRF consists of a cooling followed by a warming. For GFDL GM200 the SAM CRF is a monotonic cooling, however, with much larger uncertainty than the other models. The source of this large uncertainty lies in the fact that the
GFDL GM200 simulation displays quasi-periodic deep convective events in the SO, leading to periodicity and therefore autocorrelation in SSTs (Seviour et al. 2016; Cabré et al. 2017). Because of this quasi-periodic internal variability, it is not straightforward to estimate the uncertainty in the ozone CRF from the ensemble spread, since this is dominated by differences in ensemble member initial conditions (Seviour et al. 2016). Therefore, the ozone CRF uncertainty ranges in Fig. 4 are estimated as the standard deviation of the ensemble mean after subtracting a 15 -yr running mean.

Except for the GFDL GM200 model for time scales longer than 20 years, there is reasonably good agreement between the SAM and ozone CRFs. If, as with the ozone CRFs, we divide the SAM CRF cooling responses into multidecadal (MITgcm), decadal (GFDL GM200, GISS-E2.1), and interannual (CCSM3.5, IPSL CM5A-MR) time scales, we see that models fall into the same groupings under both approaches (the only exception being IPSL CM5A-MR for which the sign of the two CRFs disagrees after 5 years, although both responses are very weak). It is particularly noteworthy that the SAM CRFs also pick up on the large difference between GFDL GM200 and GM600 responses.

The SAM CRFs computed for the six models considered here can be compared with SAM CRFs calculated by Kostov et al. (2018) for 19 models from the CMIP5 ensemble (Fig. 5; note this shows the unscaled SAM CRFs). The GFDL GM200 model appears to be an outlier from the CMIP5 spread; however, the one CMIP5 model with a similar strong cooling response is 

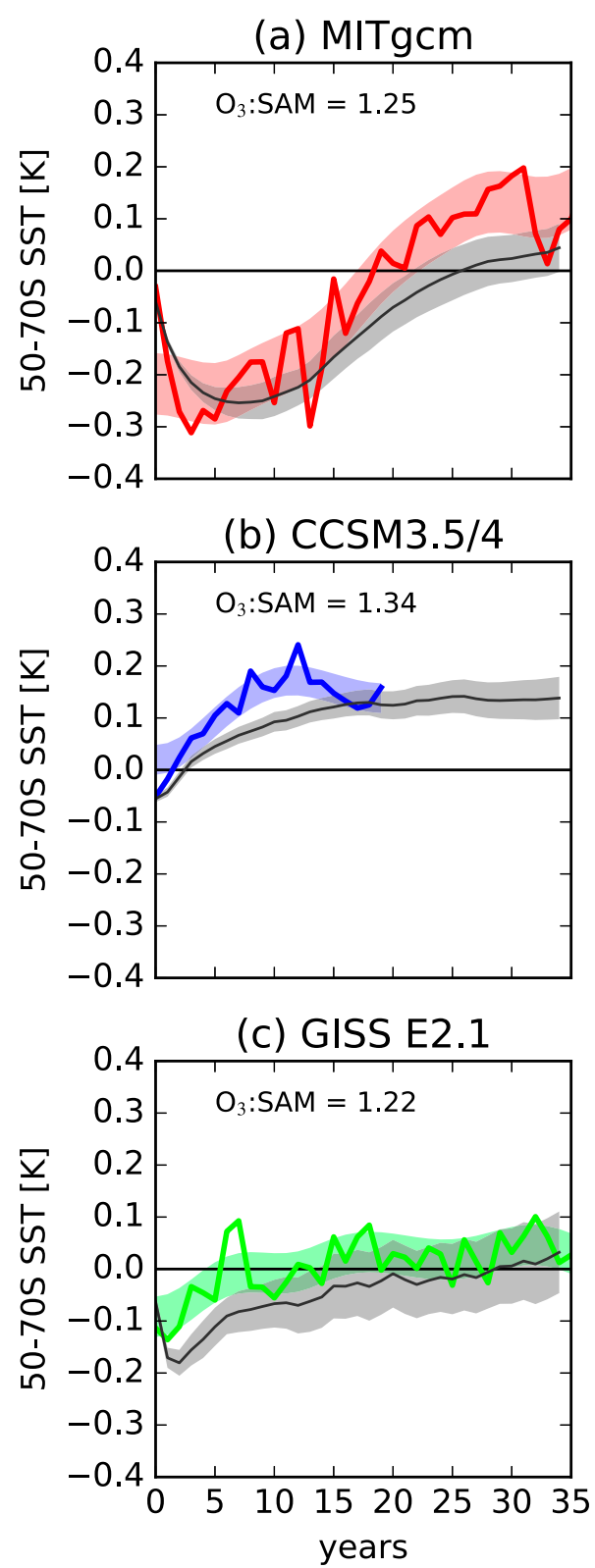

(d) GFDL ESM2Mc GM200

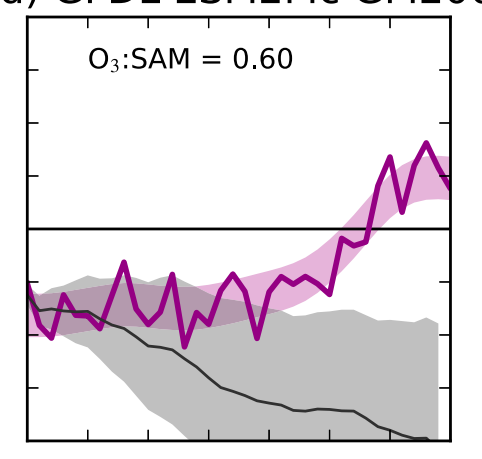

(e) GFDL ESM2Mc GM600

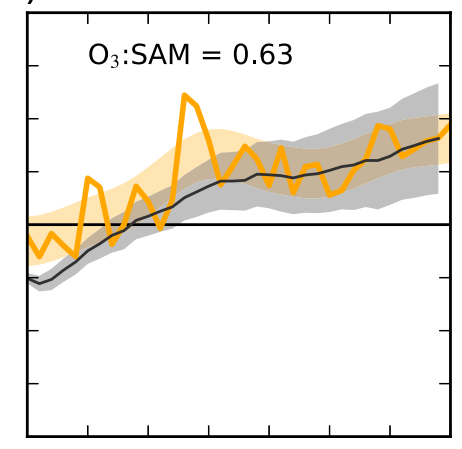

(f) IPSL CM5A-MR

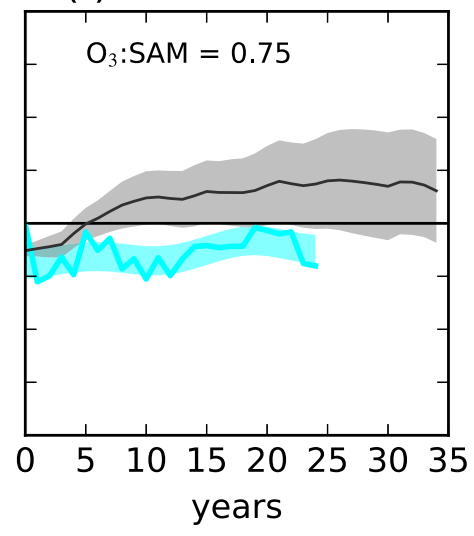

FIG. 4. Comparison of ozone CRFs and inferred SAM CRFs. Colored lines show the $50^{\circ}-$ $70^{\circ} \mathrm{S}$ annual-mean SST response to step ozone depletion for each model, as in Fig. 1. Thin black lines show the inferred SST response to a $1 \sigma$ SAM step perturbation over DecemberMay, derived from the control simulation of each model. To make the SAM and ozone responses directly comparable in magnitude, the SAM responses have been scaled by the SAM perturbation in each ozone CRF simulation (measured in standard deviations). This scaling is shown in the upper left of each plot. Shaded regions show plus and minus one standard error in the CRFs.

GFDL CM3, indicating that this response may be a feature of the GFDL model family and potentially is related to their quasi-periodic SO variability. The GFDL GM200 and GM600 SAM CRFs approximately span the entire range of CMIP5 responses, indicating a strong effect of altering the eddy advection parameterization. A third, intermediate GFDL-ESM2Mc case, GM400 (minimum $A_{\mathrm{GM}}=400 \mathrm{~m}^{2} \mathrm{~s}^{-1}$ ) is also shown in Fig. 5, and its CRF lies between the other two. In the next section we focus on understanding the relationship between models' CRFs and their climatology. Since we have shown that ozone and SAM CRFs give broadly similar results, we 


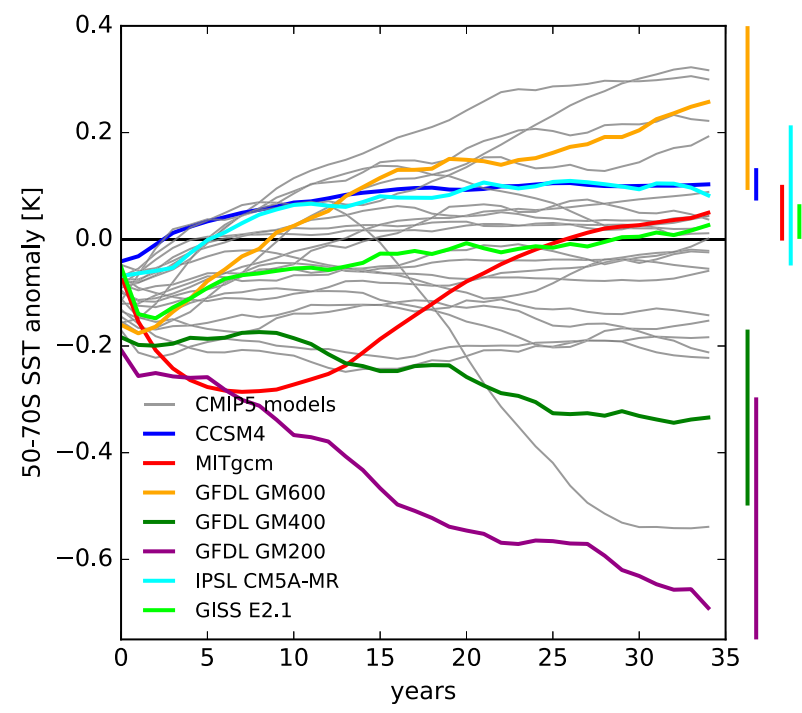

FIG. 5. Response of $50^{\circ}-70^{\circ} \mathrm{S}$ annual-mean SST to a $1 \sigma$ step perturbation in the December-May SAM, derived from model control simulations. Colored lines show the models for which ozone depletion CRFs have been calculated. Gray lines show the 19 CMIP5 simulations (data from Kostov et al. 2018). Bars at the right-hand side show the plus and minus one standard error uncertainty at year 35

hereafter focus on SAM CRFs, allowing for comparison of a wider range of models.

\section{c. Relationship between CRFs and model climatology}

The GFDL-ESM2Mc experiments with differing Gent-McWilliams coefficients $A_{\mathrm{GM}}$ allow us to probe the relationship between a model's climatology and its response to ozone depletion. Increasing $A_{\mathrm{GM}}$ leads to a flattening of isopycnals (Gent et al. 1995). In the Southern Ocean, where isopycnals slope up to the surface, the effect of increasing $A_{\mathrm{GM}}$ is therefore to reinforce the vertical density gradient, allowing for a stronger temperature inversion, as can be seen in Fig. 6a. In GFDL-ESM2Mc, increasing the $A_{\mathrm{GM}}$ minimum value from 200 to $600 \mathrm{~m}^{2} \mathrm{~s}^{-1}$ leads to an increase in the climatological annual-mean temperature inversion, $\Delta_{z}[\theta]$ (defined as the maximum vertical temperature contrast in the upper $500 \mathrm{~m}$ ) from 1.3 to $2.2 \mathrm{~K}$. Interestingly, another impact of increasing $A_{\mathrm{GM}}$ is to inhibit SO deep convective variability (Thomas et al. 2018). In the standard GM200 case, quasi-periodic deep convective variability leads to changes in annual-mean SO $\left(50^{\circ}-70^{\circ} \mathrm{S}\right) \mathrm{SST}$ of up to $2 \mathrm{~K}$, on time scales of approximately $50 \mathrm{yr}$ (Fig. 6b, purple line). For the higher mixing, GM600 case, there is no clear multidecadal variability and changes annual-mean SO SST are less than $1 \mathrm{~K}$ (orange line). The intermediate GM400 control case is also shown in Fig. 6b (green line), and can be seen to have some decadal variability, though with a lower magnitude than the GM200 case.

Kostov et al. (2017) showed that the strength of the year-1 cooling, and the rate of the subsequent warming (years 1-7) among CMIP5 SAM CRFs are correlated with the model's climatological meridional SST gradient and vertical temperature inversion, respectively. These relationships are again shown in Fig. 7 (gray points). Note that the data shown are not identical to Kostov et al. (2017) because we here consider the response to a December-May SAM perturbation (to make a closer link with the ozone response), while Kostov et al. (2017) considered an annual-mean perturbation; however, the relationships are very similar in the two cases. The linear fits shown in Fig. 7 are calculated by weighting each model by the inverse square of its uncertainty. While both slopes significantly differ from zero (according to a two-tailed $t$ test at the $95 \%$ confidence level), it is clear that the relationships fail to explain a large fraction of the intermodel spread; $R^{2}$ values are just 0.52 and 0.20 for the fast and slow responses, respectively. This is perhaps not surprising given the large number of differences between CMIP5 models that could affect the SST response to the SAM.

The perturbed Gent-McWilliams coefficient GFDLESM2Mc simulations can be used as a "clean experiment" to test the CMIP5 climatology-response relationships. Any differences between the SAM CRFs of these simulations can be unambiguously attributed to the change in eddy parameterization and its subsequent effect on the ocean climatology; other significant factors (e.g., atmospheric dynamics, cloud feedbacks, sea ice parameterization) remain constant. Altering the $A_{\mathrm{GM}}$ has little effect on the climatological meridional SST gradient, and, consistent with Kostov et al. (2017), the fast time scale responses of all three cases agree to within error (Fig. 7a, colored points). However, as discussed above, a higher $A_{\mathrm{GM}}$ leads to a stronger temperature inversion, so given the relationship among CMIP5 models, we would expect a faster warming rate for higher $A_{\mathrm{GM}}$. This is indeed found (Fig. 7b). The difference among the warming rates of the three $A_{\mathrm{GM}}$ cases is slightly greater than would be predicted from the CMIP5 regression, although the regression coefficients agree to within error. This result lends support that correlations found by Kostov et al. (2017) are indeed causal relationships.

An additional factor that may contribute to the large intermodel spread in SAM CRFs is differences in cloudcirculation feedbacks and their subsequent impact on shortwave radiation. Grise and Polvani (2014) studied cloud-radiative anomalies associated with shifts in the latitude of the Southern Hemisphere extratropical jet 

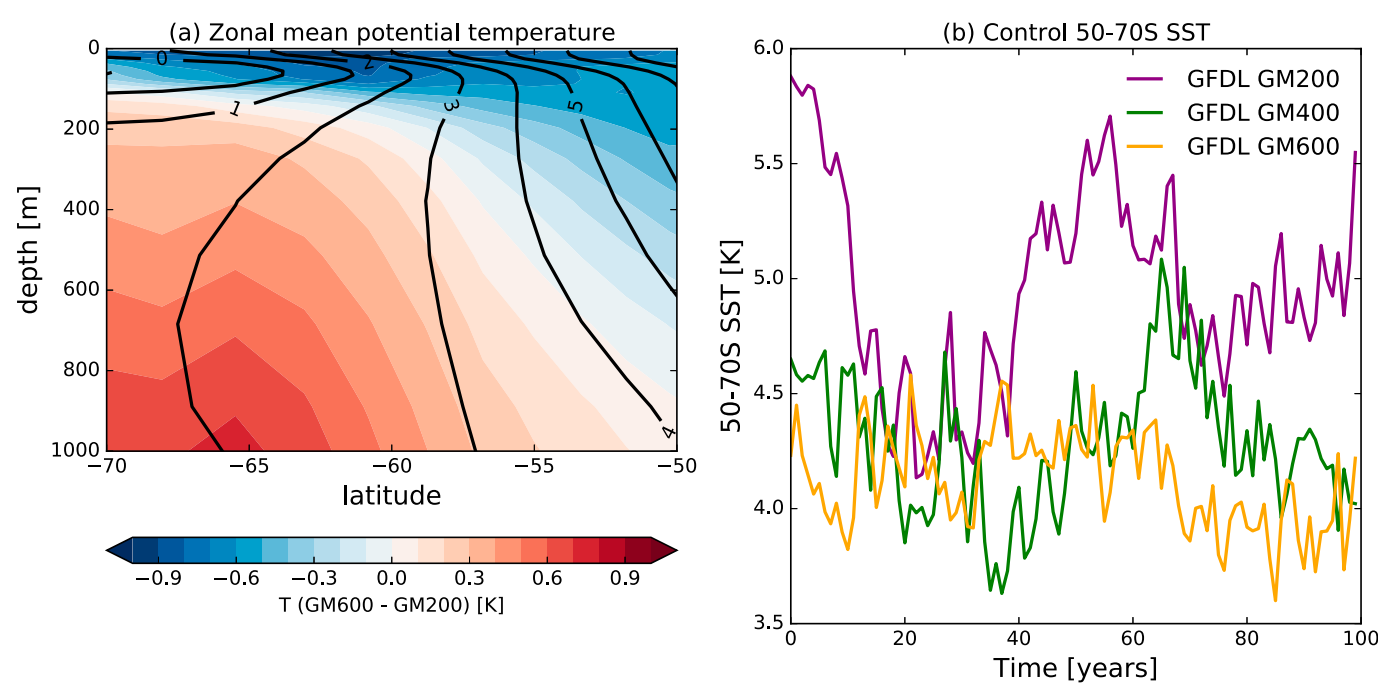

FIG. 6. Comparison of GFDL-ESM2Mc control simulations with different GM parameter minimum values. (a) Zonal-mean potential temperature for the GM200 simulation (black contours, ${ }^{\circ} \mathrm{C}$ ) and anomalies of the GM600 simulation relative to GM200 (colors). (b) Time series of 100 years of $50^{\circ}-70^{\circ} \mathrm{S}$ annual-mean SST.

among CMIP5 models. They quantified this effect through a jet-cloud radiative effect (CRE) index (jetCRE), defined as the change in CRE averaged over $30^{\circ}-60^{\circ} \mathrm{S}$ associated with a $1^{\circ}$ poleward shift of the jet, where the CRE is the change in top-of-atmosphere outgoing radiation between clear-sky and all-sky scenarios (Ramanathan et al. 1989). CMIP5 models can be divided into two groups; those for which a poleward shift of the jet leads to a reduction in midlatitude cloud fraction and a subsequent shortwave surface warming (jet-CRE index $>0$ ), and those for which this warming effect is largely absent (jet-CRE index $<0$ ). Seviour et al. (2017a) showed that a reduction in shortwave heating plays an important role in driving the short-term
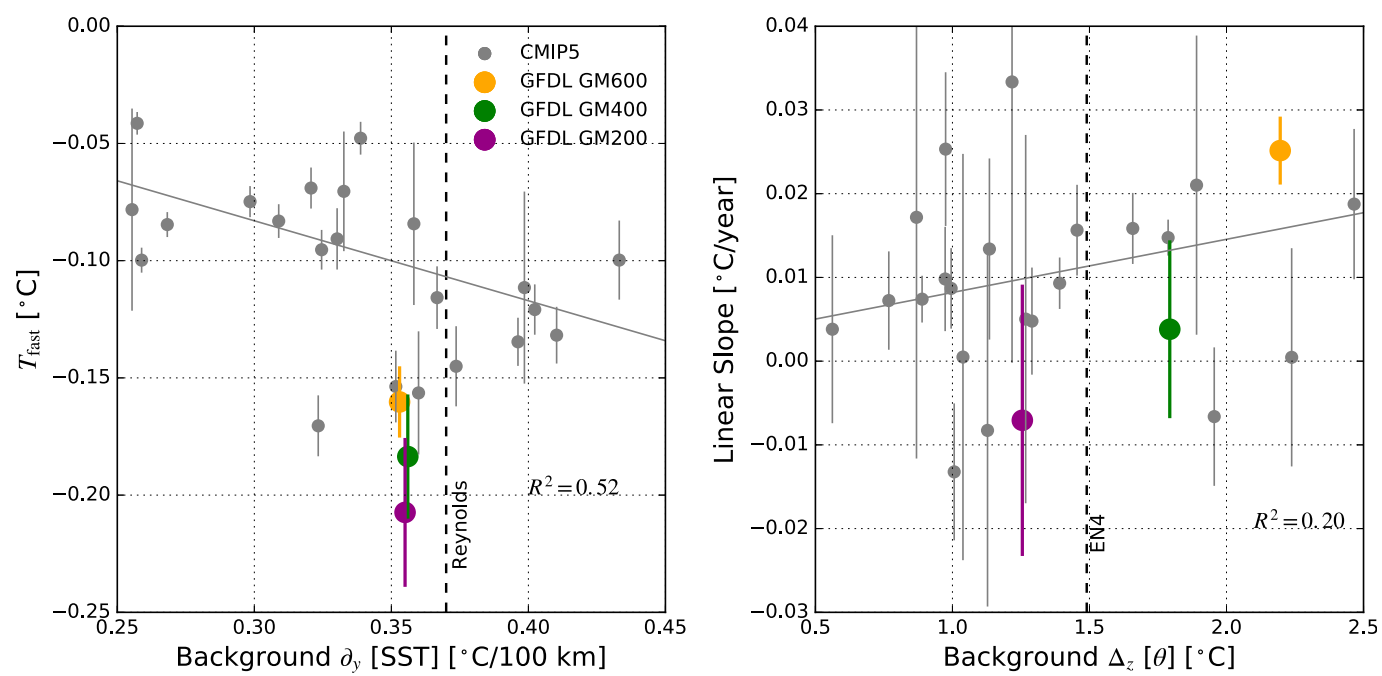

FIG. 7. Relationship between model climatology and response to a December-May step SAM perturbation. (a) Fast (year 1) $50^{\circ}-70^{\circ} \mathrm{S} \mathrm{SST}$ response to the SAM perturbation against the climatological (control simulation) meridional SST gradient over $50^{\circ}-70^{\circ} \mathrm{S}$. (b) Trend in SST from years 1-7 following the SAM perturbation against the climatological annual-mean temperature inversion (i.e., maximum vertical temperature contrast) between $67-$ and 510-m depths. Error bars show plus and minus one standard error. The gray line shows the linear fit to the CMIP5 models' scatter, where each model has been weighted by the inverse of its standard error squared; the $R^{2}$ value for this linear regression is shown in each panel. Observational estimates [using data from the NOAA Reynolds Optimum Interpolation (Reynolds et al. 2002) and Hadley Centre EN4 dataset (Good et al. 2013)] are indicated by the vertical dashed lines. 
(a)

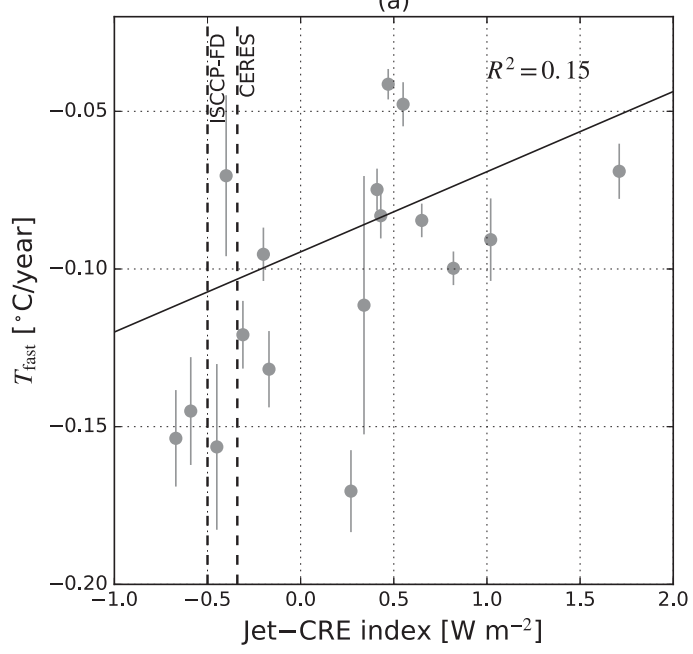

(b)

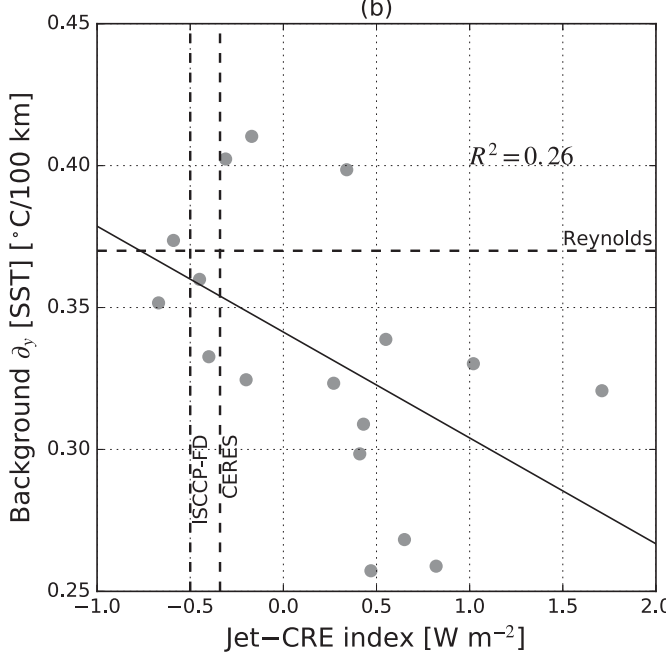

FIG. 8. (a) Fast (year 1) $50^{\circ}-70^{\circ} \mathrm{S}$ SST response to the December-May SAM perturbation (as in Fig. 7a) against the December-March jet-CRE index for 17 CMIP5 models reported by Grise and Polvani (2014). (b) Climatological meridional SST gradient over $50^{\circ}-70^{\circ} \mathrm{S}$ (as in Fig. 7a) against the jet-CRE index for the same models. Data for the jetCRE index are from Grise and Polvani (2014). Correlation coefficients are shown in the upper right of each figure. Two observational estimates of the jet-CRE index from Grise and Polvani (2014) are shown, using either radiative fluxes from the International Satellite Cloud Climatology Project (ISCCP; Zhang et al. 2004) or Clouds and Earth's Radiant Energy System (CERES; Loeb et al. 2012) experiment. As in Fig. 7a, the observational estimate of the meridional SST gradient from Reynolds et al. (2002) is shown by the horizontal line in (b).

SST cooling response to ozone depletion in GFDLESM2Mc. Motivated by this result we here show the relationship between CMIP5 models' December-March jet-CRE indices and their year-1 SST cooling in the SAM CRF (Fig. 8a). A positive correlation, which statistically significant (at the $95 \%$ level), can be seen. Although the $R^{2}$ value of 0.15 is less than those in Fig. 7, the sign of the correlation is physically intuitive. Models with a positive jet-CRE index display a shortwave warming associated with a poleward jet shift (positive SAM) that opposes the SST cooling response. Models with a negative jet-CRE index have a net shortwave cooling associated with the SAM perturbation, leading to a stronger SST cooling. Following Grise and Polvani (2014), two observational jet-CRE index estimates are indicated in Fig. 8a. These are both negative $\left(-0.5 \mathrm{~W} \mathrm{~m}^{-2}\right.$ for ISCCP-FD, and $-0.34 \mathrm{~W} \mathrm{~m}^{-2}$ for CERES), thereby favoring a stronger short-term cooling response to the SAM perturbation.

Complicating the relationship shown in Fig. 8a, is the fact that CMIP5 models' jet-CRE indices and their background SST gradients are themselves statistically significantly correlated (Fig. 8b). Models with a negative jet-CRE index generally have a stronger SST gradient than those with a positive jet-CRE index. It is therefore unclear whether the relationship shown in Fig. $8 \mathrm{a}$ is causal, meaning jet-CRE feedbacks directly affect the SST response to SAM. To test the causality of the relationship it will be necessary to construct an experiment in which only cloud feedbacks are perturbed, without changing the SST climatology; a similar approach to the perturbed $A_{\mathrm{GM}}$ experiments described above.

\section{Discussion and implications for sea ice}

A major motivation for this study has been understanding the extent to which ozone depletion may have contributed toward the surprising multidecadal cooling of SO SST since about 1980 (Fan et al. 2014; Fig. S2). We have shown that even models with a long ( $\sim 30$ years) SST cooling response to a step ozone perturbation do not predict a cooling from 1980 to the present in response to realistic ozone changes, rather they show a warming trend from at least as early as the mid-1990s (Fig. 3). Hence, if ozone depletion were to be the driving the observed SST trend, then the climate system must exhibit a cooling phase that is longer than that of any of the models, or have a monotonic cooling response, with no long-term warming. However, the position of the observed SO climatology among the climatology-response relationships shown in Fig. 7b indicates that this is unlikely to be the case. The observed estimate for the strength of the SO temperature inversion lies toward the middle of the CMIP5 model spread, and between the GM200 and GM400 

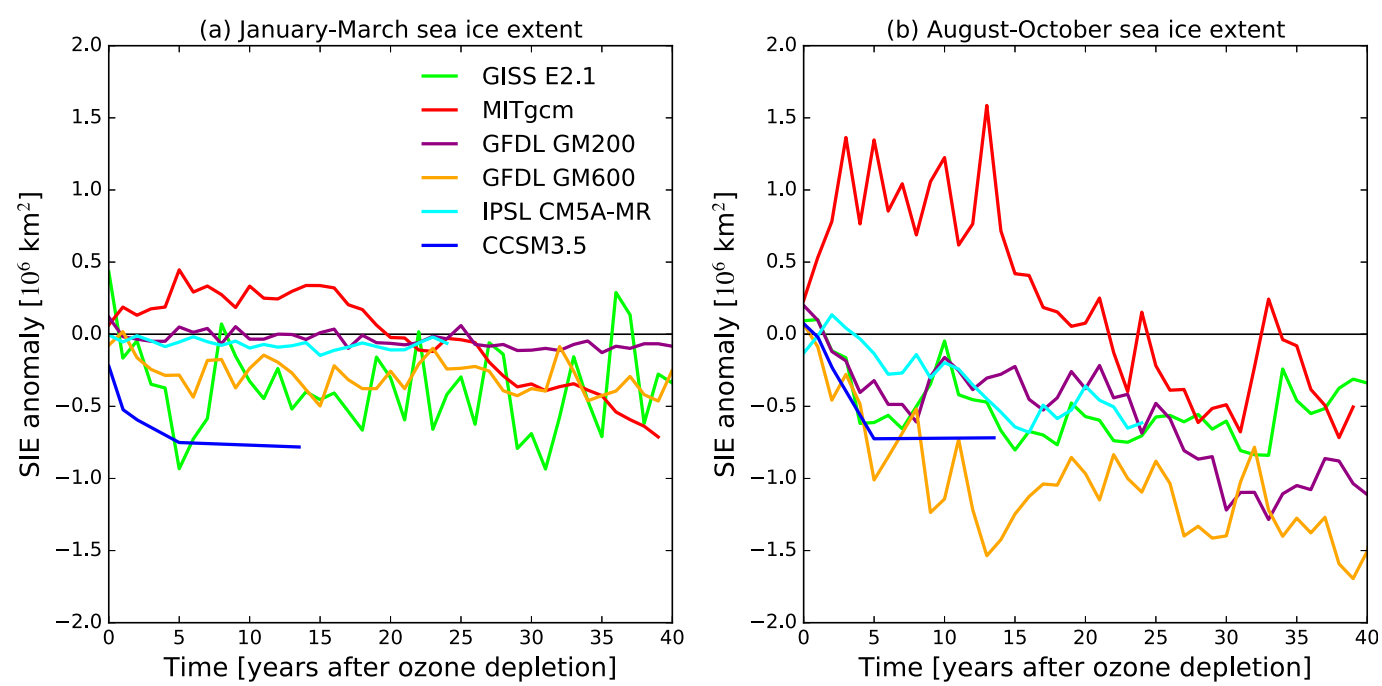

FIG. 9. Ensemble-mean anomalies of (a) January-March and (b) August-October Southern Hemisphere sea ice extent (SIE) in each ozone depletion CRF simulation.

GFDL-ESM2Mc experiments. This favors a slightly positive SST trend over years 1-7 following the step perturbation, not the cooling that would be needed to reproduce the observed SST trend. However, it is of course possible that the climate system is an outlier from the relationship shown in Fig. 7b, possessing a stronger long-term cooling response than would be expected from its climatological temperature inversion. Indeed, this might be the case if eddy compensation counteracts the wind-driven upwelling of warm subsurface water (Doddridge et al. 2019), a process that may not be well captured by the models analyzed here.

An alternative explanation for the observed SST cooling is that it is the result of other processes or internal climate variability. It should be noted that this internal variability would have to be sufficiently strong to overcome both the likely warming trend induced by ozone depletion, as well as the warming effect of rising greenhouse gas concentrations. Kostov et al. (2018) estimated this greenhouse gas-driven warming of SO SST to be approximately $0.04^{\circ} \mathrm{C}$ decade ${ }^{-1}$ over $1979-2014$. We have shown here that models vary greatly in their magnitudes and time scales of SO internal variability, and that this variability is highly sensitive to the parameterization of subgrid-scale mixing (Fig. 6). The most variable GFDL-ESM2Mc experiment (GM200) showed SO SST changes of nearly $2 \mathrm{~K}$ over periods of about 50 years. However, even the least variable case (GM600) has changes of about $0.5 \mathrm{~K}$ over 50 years. Such changes would be more than sufficient to explain the observed 30-yr cooling of about $0.15 \mathrm{~K}$ since 1980 .

We have focused exclusively on the SST response to ozone depletion and so have not presented a detailed discussion of accompanying sea ice changes. However, it might be assumed that there is a strong relation between the two quantities, and models that have a stronger SST cooling response show a greater sea ice expansion. Responses of summer and winter sea ice extent are shown for each of the ozone CRF experiments in Fig. 9, revealing that the SST-sea ice relationship is not so straightforward. In fact, only one model shows a sea ice expansion beyond the first year after ozone depletion in either the summer or winter (MITgcm), despite the fact that most models show a $50^{\circ}-70^{\circ} \mathrm{S}$ average SST cooling lasting several years.

This apparent conflict between SST and sea ice changes may result from SST changes being largely equatorward of the sea ice edge [as shown by Seviour et al. (2016) for GFDL-ESM2Mc], or from zonal asymmetries in the SST response. Indeed, it should be noted that the small yet significant observed Antarctic sea ice expansion over recent decades is the result of two almost-cancelling regional trends, with the largest expansion in the Ross Sea, and the largest decline in the Bellingshausen and Amundsen Seas (Hobbs et al. 2016). Following a similar approach to Kostov et al. (2017), Holland et al. (2016) used lagged linear regression to investigate the response of sea ice extent to a step SAM perturbation in the CMIP5 ensemble. They found that the majority of models exhibit a twotime-scale response, with an initial sea ice expansion followed by a decline. The fact that this two-time-scale response is only seen in one ozone CRF experiment (for the nearly zonally symmetric MITgcm) suggests that the relationship between ozone and SAM CRFs may be less strong in the case of sea ice, potentially the 
result of regional impacts of ozone depletion that do not project on to the SAM.

\section{Conclusions}

Here we have examined the impact of ozone depletion on SO SST, with a particular emphasis on the time dependence of the response through the calculation of CRFs; responses to instantaneous step changes in forcing. Our synthesis of recently published studies, alongside several new simulations, has revealed the following:

1) Two recent approaches for estimating the transient impact of ozone depletion on Southern Ocean SST broadly agree on the time scales and magnitudes of the response. The first approach simulates the fully nonlinear CRF for an explicit ozone perturbation (Ferreira et al. 2015; Seviour et al. 2016, 2017a), while the second infers the CRF through lagged linear regression of the SAM and SST (Kostov et al. $2017,2018)$. Note that it is not immediately obvious that these two approaches should have given similar results since the linear approach neglects potentially important feedbacks between the SAM and SST and assumes that the tropospheric response to ozone depletion can be approximated by a SAM perturbation.

2) While almost all models show a two-time-scale response to an ozone perturbation, consisting of a short-term cooling followed by a long-term warming, we find large intermodel spread (duration of cooling ranges from 2 to 30 years). When considering the SST response to realistic time-varying ozone changes, this CRF uncertainty results in an uncertainty even as to the sign of the response (i.e., whether it is a cooling or a warming).

3) We provide further evidence to support the finding of Kostov et al. (2017) that biases among models' CRFs are related to biases in their SO climatology, with the short-term response being related to the meridional SST gradient, and the long-term response related to the strength of the SO temperature inversion. Experiments with perturbed subgrid-scale mixing (Gent-McWilliams parameter minimum) confirm this relationship, and highlight that a perturbation to a single parameter within a single model can cause a change to the CRF that approximately spans the range of CMIP5 responses. Cloud-circulation feedbacks may also play a significant role in model CRF biases, but since they are also related to the SO climatology, untangling these effects is not straightforward.

4) Combining the climatology-response relationship in models with observed climatological values allows us to constrain the likely forced response of the real climate system. Although there are significant uncertainties, such an analysis suggests that ozone depletion is unlikely to have driven the observed SO SST cooling trend from 1980 to the present. Many models produce internal multidecadal SO SST trends of sufficient magnitude to explain the observed trend.

While the climatology-response relationships shown in Figs. 7 and 8 have gone some way to understanding the large diversity of model CRFs, it is clear that a significant fraction of the intermodel variance remains unexplained. It is challenging to pin down the causes of uncertainty in multimodel ensembles because many factors differ between models. Using the perturbed $A_{\mathrm{GM}}$ experiments shown here we were able to unambiguously attribute one potential driver of intermodel diversity. Extending this approach to other important processes (e.g., cloud feedbacks, air-sea heat fluxes, sea ice) provides a way forward for understanding and reducing intermodel uncertainty.

Acknowledgments. This work was supported by the National Science Foundation under NSF proposal FESD-1338814. Data from the CRF simulations analyzed here are available from the authors on request. CMIP5 data used in this study are freely available through the Earth System Grid Federation (https://esgfnode.llnl.gov).

\section{REFERENCES}

Armour, K. C., and C. M. Bitz, 2015: Observed and projected trends in Antarctic sea ice. US CLIVAR Variations, Vol. 13, No. 4, U.S. Climate Variability and Predictability Program, Washington, DC, 13-19.

Barnes, E. A., and L. M. Polvani, 2013: Response of the midlatitude jets, and of their variability, to increased greenhouse gases in the CMIP5 models. J. Climate, 26, 7117-7135, https://doi.org/ 10.1175/JCLI-D-12-00536.1.

Bitz, C. M., and L. M. Polvani, 2012: Antarctic climate response to stratospheric ozone depletion in a fine resolution ocean climate model. Geophys. Res. Lett., 39, L20705, https://doi.org/ 10.1029/2012GL053393.

Cabré, A., I. Marinov, and A. Gnanadesikan, 2017: Global atmospheric teleconnections and multi-decadal climate oscillations driven by Southern Ocean convection. J. Climate, 30, 81078126, https://doi.org/10.1175/JCLI-D-16-0741.1.

Ciasto, L. M., and D. W. Thompson, 2008: Observations of largescale ocean-atmosphere interaction in the Southern Hemisphere. J. Climate, 21, 1244-1259, https://doi.org/10.1175/ 2007JCLI1809.1.

Cionni, I., and Coauthors, 2011: Ozone database in support of CMIP5 simulations: Results and corresponding radiative forcing. Atmos. Chem. Phys., 11, 11 267-11 292, https://doi.org/ 10.5194/acp-11-11267-2011.

Doddridge, E. W., J. Marshall, H. Song, M. Kelley, and L. Nazarenko, 2019: Eddy compensation dampens Southern 
Ocean SST response to westerly wind trends. Geophys. Res. Lett., 46, https://doi.org/10.1029/2019GL082758.

Dufresne J.-L., and Coauthors, 2013: Climate change projections using the IPSL-CM5 Earth system model: From CMIP3 to CMIP5. Climate Dyn., 40, 2123-2165, https://doi.org/10.1007/ s00382-012-1636-1.

Fan, T., C. Deser, and D. P. Schneider, 2014: Recent Antarctic sea ice trends in the context of Southern Ocean surface climate variations since 1950. Geophys. Res. Lett., 41, 2419-2426, https://doi.org/10.1002/2014GL059239.

Ferreira, D., J. Marshall, C. M. Bitz, S. Solomon, and A. Plumb, 2015: Antarctic Ocean and sea ice response to ozone depletion: A two-time-scale problem. J. Climate, 28, 1206-1226, https://doi.org/10.1175/JCLI-D-14-00313.1.

Froidevaux, L., D. E. Kinnison, R. Wang, J. Anderson, and R. A. Fuller, 2019: Evaluation of CESM1 (WACCM) free-running and specified-dynamics atmospheric composition simulations using global multi-species satellite data records. Atmos. Chem. Phys., 19, 4783-4821, https://doi.org/10.5194/acp-19-4783-2019.

Gent, P. R., and J. C. McWilliams, 1990: Isopycnal mixing in ocean circulation models. J. Phys. Oceanogr., 20, 150-155, https:// doi.org/10.1175/1520-0485(1990)020<0150:IMIOCM > 2.0.CO;2.

_ J. Willebrand, T. J. McDougall, and J. C. McWilliams, 1995: Parameterizing eddy-induced tracer transports in ocean circulation models. J. Phys. Oceanogr., 25, 463-474, https://doi.org/ 10.1175/1520-0485(1995)025<0463:PEITTI>2.0.CO;2.

Gerber, E. P., and S. Son, 2014: Quantifying the summertime response of the austral jet stream and Hadley cell to stratospheric ozone and greenhouse gases. J. Climate, 27, 5538-5559, https://doi.org/10.1175/JCLI-D-13-00539.1.

Good, S. A., M. J. Martin, and N. A. Rayner, 2013: EN4: Quality controlled ocean temperature and salinity profiles and monthly objective analyses with uncertainty estimates. J. Geophys. Res., 118, 6704-6716, https://doi.org/10.1002/2013JC009067.

Goosse, H., W. Lefebvre, A. de Montety, E. Crespin, and A. H. Orsi, 2009: Consistent past half-century trends in the atmosphere, the sea ice and the ocean at high southern latitudes. Climate Dyn., 33, 999-1016, https://doi.org/10.1007/s00382-008-0500-9.

Grise, K. M., and L. M. Polvani, 2014: Southern Hemisphere cloud-dynamics biases in CMIP5 models and their implications for climate projections. J. Climate, 27, 6074-6092, https:// doi.org/10.1175/JCLI-D-14-00113.1.

Hall, A., and M. Visbeck, 2002: Synchronous variability in the Southern Hemisphere atmosphere, sea ice, and ocean resulting from the annular mode. J. Climate, 15, 3043-3057, https://doi.org/ 10.1175/1520-0442(2002)015<3043:SVITSH > 2.0.CO;2.

Hande, L. B., S. T. Siems, and M. J. Manton, 2012: Observed trends in wind speed over the Southern Ocean. Geophys. Res. Lett., 39, L11802, https://doi.org/10.1029/2012GL051734.

Hasselmann, K., 1993: Optimal fingerprints for the detection of timedependent climate change. J. Climate, 6, 1957-1971, https:// doi.org/10.1175/1520-0442(1993)006<1957:OFFTDO >2.0.CO;2.

Hobbs, W. R., R. Massom, S. Stammerjohn, P. Reid, G. Williams, and W. Meier, 2016: A review of recent changes in Southern Ocean sea ice, their drivers and forcings. Global Planet. Change, 143, 228-250, https://doi.org/10.1016/j.gloplacha.2016.06.008.

Holland, M. M., L. Landrum, Y. Kostov, and J. Marshall, 2016: Sensitivity of Antarctic sea ice to the southern annular mode in coupled climate models. Climate Dyn., 49, 1813-1831, https://doi.org/10.1007/s00382-016-3424-9.

Jones, J. M., and Coauthors, 2016: Assessing recent trends in highlatitude Southern Hemisphere surface climate. Nat. Climate Change, 6, 917-926, https://doi.org/10.1038/nclimate3103.
Kostov, Y., J. Marshall, U. Hausmann, K. C. Armour, D. Ferreira, and M. M. Holland, 2017: Fast and slow responses of Southern Ocean sea surface temperature to SAM in coupled climate models. Climate Dyn., 48, 1595-1609, https://doi.org/10.1007/ s00382-016-3162-z.

— , D. Ferreira, K. C. Armour, and J. Marshall, 2018: Contributions of greenhouse gas forcing and the southern annular mode to historical Southern Ocean surface temperature trends. Geophys. Res. Lett., 45, 1086-1097, https://doi.org/ 10.1002/2017GL074964.

Loeb, N. G., S. Kato, W. Su, T. Wong, F. G. Rose, D. R. Doelling, J. R. Norris, and X. Huang, 2012: Advances in understanding top-of-atmosphere radiation variability from satellite observations. Surv. Geophys., 33, 359-385, https://doi.org/10.1007/ s10712-012-9175-1.

Marshall, J., K. C. Armour, J. R. Scott, Y. Kostov, U. Hausmann, D. Ferreira, T. G. Shepherd, and C. M. Bitz, 2014: The ocean's role in polar climate change: Asymmetric Arctic and Antarctic responses to greenhouse gas and ozone forcing. Philos. Trans. Roy. Soc., 372A, 20130040, https://doi.org/10.1098/rsta.2013.0040.

Meehl, G. A., J. M. Arblaster, C. T. Y. Chung, M. M. Holland, A. DuVivier, L. Thompson, D. Yang, and C. M. Bitz, 2019: Sustained ocean changes contributed to sudden Antarctic sea ice retreat in late 2016. Nat. Commun., 10, 14, https://doi.org/ 10.1038/s41467-018-07865-9.

Polvani, L. M., D. W. Waugh, G. J. Correa, and S. Son, 2011: Stratospheric ozone depletion: The main driver of twentieth-century atmospheric circulation changes in the Southern Hemisphere. J. Climate, 24, 795-812, https://doi.org/10.1175/2010JCLI3772.1.

Previdi, M., and L. M. Polvani, 2014: Climate system response to stratospheric ozone depletion and recovery. Quart. J. Roy. Meteor. Soc., 140, 2401-2419, https://doi.org/10.1002/qj.2330.

Ramanathan, V., R. D. Cess, E. F. Harrison, P. Minnis, B. R. Barkstrom, E. Ahmad, and D. Hartmann, 1989: Cloud radiative forcing and climate: Results from the Earth Radiation Budget Experiment. Science, 243, 57-63, https://doi.org/ 10.1126/science.243.4887.57.

Reynolds, R. W., N. A. Rayner, T. M. Smith, D. C. Stokes, and W. Wang, 2002: An improved in situ and satellite SST analysis for climate. J. Climate, 15, 1609-1625, https://doi.org/10.1175/ 1520-0442(2002)015<1609:AIISAS > 2.0.CO;2.

Seviour, W. J. M., A. Gnanadesikan, and D. W. Waugh, 2016: The transient response of the Southern Ocean to stratospheric ozone depletion. J. Climate, 29, 7383-7396, https://doi.org/ 10.1175/JCLI-D-16-0198.1.

$-, \ldots,-\longrightarrow$, and M.-A. Pradal, 2017a: Transient response of the Southern Ocean to changing ozone: Regional responses and physical mechanisms. J. Climate, 30, 2463-2480, https:// doi.org/10.1175/JCLI-D-16-0474.1.

— D. W. Waugh, L. M. Polvani, G. J. Correa, and C. I. Garfinkel, 2017b: Robustness of the simulated tropospheric response to ozone depletion. J. Climate, 30, 2577-2585, https:// doi.org/10.1175/JCLI-D-16-0817.1.

Sigmond, M., and J. C. Fyfe, 2010: Has the ozone hole contributed to increased Antarctic sea ice extent? Geophys. Res. Lett., 37, L18502, https://doi.org/10.1029/2010GL044301.

— and - 2014: The Antarctic sea ice response to the ozone hole in climate models. J. Climate, 27, 1336-1342, https:// doi.org/10.1175/JCLI-D-13-00590.1.

Smith, K. L., L. M. Polvani, and D. R. Marsh, 2012: Mitigation of 21st century Antarctic sea ice loss by stratospheric ozone recovery. Geophys. Res. Lett., 39, L20701, https://doi.org/ 10.1029/2012GL053325. 
Solomon, A., L. M. Polvani, K. L. Smith, and R. P. Abernathey, 2015: The impact of ozone depleting substances on the circulation, temperature, and salinity of the Southern Ocean: An attribution study with CESM1(WACCM). Geophys. Res. Lett., 42, 55475555, https://doi.org/10.1002/2015GL064744.

Swart, N. C., and J. C. Fyfe, 2012: Observed and simulated changes in the Southern Hemisphere surface westerly wind-stress. Geophys. Res. Lett., 39, L16711, https://doi.org/10.1029/ 2012GL052810.

,,-- N. Gillett, and G. J. Marshall, 2015: Comparing trends in the southern annular mode and surface westerly jet. J. Climate, 28, 8840-8859, https://doi.org/10.1175/JCLI-D-15-0334.1.

Thomas, J. L., D. W. Waugh, and A. Gnanadesikan, 2015: Southern Hemisphere extratropical circulation: Recent trends and natural variability. Geophys. Res. Lett., 42, 5508-5515, https:// doi.org/10.1002/2015GL064521. and - 2018: Relationship between ocean carbon and heat multidecadal variability. J. Climate, 31, 1467-1482, https://doi.org/10.1175/JCLI-D-17-0134.1.

Thompson, D. W. J., and S. Solomon, 2002: Interpretation of recent Southern Hemisphere climate change. Science, 296, 895-899, https://doi.org/10.1126/science.1069270.

- — - P. J. Kushner, M. H. England, K. Grise, and D. J. Karoly, 2011: Signatures of the Antarctic ozone hole in Southern Hemisphere surface climate change. Nat. Geosci., 4, 741-749, https://doi.org/10.1038/ngeo1296.

Zhang, Y. C., W. B. Rossow, A. A. Lacis, V. Oinas, and M. I. Mishchenko, 2004: Calculation of radiative fluxes from the surface to top of atmosphere based on ISCCP and other global data sets: Refinements of the radiative transfer model and the input data. J. Geophys. Res., 109, D19105, https://doi.org/ 10.1029/2003JD004457. 